\title{
OPTIMASI CITRA DICOM DENGAN MENGGUNAKAN APLIKASI PADA SMARTPHONE ANDROID
}

\author{
Samuel Gideon, Taat Guswantoro \\ Program Studi Program Studi Pendidikan Fisika, Fakultas Keguruan dan Ilmu Pendidikan Universitas \\ Kristen Indonesia \\ Jl.Mayjen Soetoyo No.2, Cawang \\ Email: mysuperemail1988@gmail.com
}

\begin{abstract}
A radiographic image is generated from a mapping of attenuation of $X$-ray beam that passed through a material. Over the past few years, as computer acquisition technology has grown, conventional diagnostic medical imaging modalities have increasingly been replaced by digital imagery. Computed radiography $(C R)$ is one of radiographic image acquisition using computers. $C R$ images could be either .jpg files or DICOM files. We exposed some wrenches which diameter of 5.68 $\mathrm{mm} ; 3.99 \mathrm{~mm}$ and $3.2 \mathrm{~mm}$ as well as a bottle and a circular cork. We use Siemens mobile x-ray to expose the objects and DroidRender 3D DICOM Viewer as the DICOM viewer. We got two images which are .jpg file and DICOM file respectively. We adjust WW and WL parameters in order to optimize the image of DICOM file. The results are $W W=2833$ and $W C=2170$.
\end{abstract}

Keywords: type your keywords here...3-5 keywords, Algorithm A, B algorithms, complexity

Abstrak: Citra medis yang dihasilkan oleh sistem radiografi pada dasarnya adalah pemetaan dari berkas sinar-X yang diteruskan yang dinyatakan melalui hukum penurunan intensitas sinar-X. Selama beberapa tahun terakhir, dengan semakin berkembangnya teknologi akuisisi komputer, modalitas pencitraan medis diagnostik konvensional semakin digantikan oleh citra digital. Computed radiography $(\mathrm{CR})$ merupakan salah satu teknologi akuisisi komputer pengolah citra radiografi. Hasil citra radiografi pada CR dapat berbentuk file .jpg ataupun DICOM. Untuk membaca file DICOM harus digunakan DICOM viewer yang dapat diunduh secara gratis dari internet. Pada penelitian ini, obyek-obyek yang dipapari sinar-X yaitu kunci inggris dengan tebal diameter 5,68 $\mathrm{mm} ; 3,99 \mathrm{~mm}$ dan 3,2 $\mathrm{mm}$ serta botol dan gabus berbentuk lingkaran. Pesawat sinar-X yang digunakan adalah mobile $x$ ray bermerk Siemens. Aplikasi DICOM viewer yang digunakan adalah DroidRender 3D DICOM Viewer. Dari hasil eksperimen, pengaturan WW dan WC pada aplikasi untuk dapat menampilkan gabus secara optimal diperoleh pada nilai $\mathrm{WW}=2833$ dan $\mathrm{WC}=2170$.

Kata kunci: Dicom, DroidRender 3D DICOM Viewer, Sinar X

\section{PENDAHULUAN}

Sinar-X ketika menembus materi akan mengalami penurunan intensitas yang mana sesuai dengan karakteristik obyek yang dilaluinya. Citra medis yang dihasilkan oleh sistem radiografi pada dasarnya adalah pemetaan dari berkas sinar-X yang diteruskan $I$, berkas sinar$\mathrm{X}$ mula-mula yang datang Io, tebal obyek $x$ dan kepadatan obyek yang dipapari sinar-X $\lambda$, yang secara matematis dinyatakan melalui hukum penurunan intensitas sinar-X:

$$
I=I_{0} e^{(-\lambda x)}
$$

Selama beberapa tahun terakhir, dengan semakin berkembangnya teknologi akuisisi komputer, modalitas pencitraan medis diagnostik konvensional semakin digantikan oleh citra digital (Hermen dkk, 2010). Salah satu keunggulan dari sistem citra digital dibandingkan dengan sistem citra konvensional antara lain menekan biaya operasional karena tidak lagi 
menggunakan banyak film serta meningkatkan jangkauan dinamis dari citra yang diperoleh (Susilo dkk, 2013; Ningtias dkk, 2016). Selain itu, citra digital dapat langsung diamati, mudah disimpan dan digunakan, karena terhubung langsung dengan sistem komputer sehingga sifatnya ramah lingkungan (Suryaningsih dkk, 2015).

Computed radiography (CR) merupakan salah satu teknologi akuisisi komputer pengolah citra radiografi. Skema pencitraan pada CR dapat dilihat pada Gambar 1.

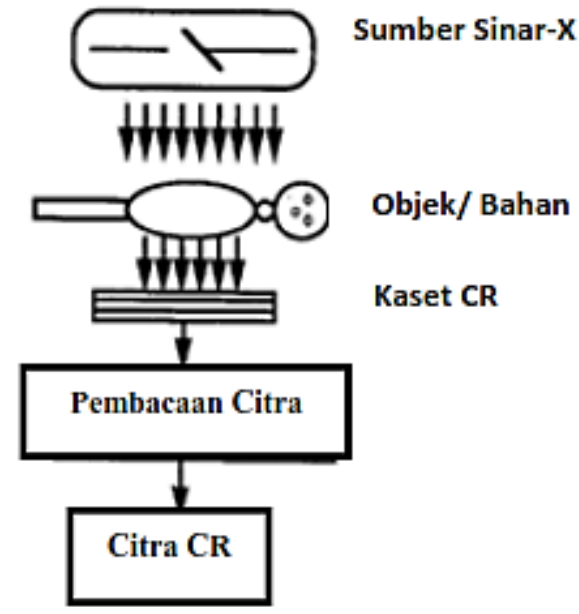

Gambar 1. Skema sistem CR dari paparan sinar-X hingga mendapatkan citra (Ningtias, 2016)

Pada CR, hasil citra radiografi tersimpan dalam suatu kaset film khusus dan dinyatakan dalam bentuk tingkat keabuan piksel citra. Hasil citra radiografi dalam kaset film tersebut kemudian dibaca oleh pemindai (scanner) dan selanjutnya dapat ditampilkan di layar monitor PC. Citra radiografi tersebut dapat disimpan dalam bentuk file gambar biasa yang berekstensi .png atau .jpg serta suatu format file digital khusus yang dinamakan DICOM (Digital Imaging and Communications in Medicine).

DICOM memiliki file ekstensi .dcm yang tidak dapat dibaca oleh sistem operasi pada PC yang banyak digunakan seperti Windows ataupun Linux. Oleh karena itu, untuk membaca file DICOM harus digunakan DICOM viewer yang dapat diunduh secara gratis dari internet. Beberapa penelitian yang terkait dengan penggunaan DICOM viewer antara lain adalah Kristianto (2010) yang mengkaji tentang penggunaan format DICOM untuk mengatasi perbedaan kompatibilitas dalam penyimpanan data rekam medis dan Ningtias dkk (2016) yang mengukur kualitas citra digital computed radiography menggunakan program MATLAB. Bahkan, Yogianto dkk (2012) merancang aplikasi DICOM viewer yang terintegrasi dengan sistem CR di rumah sakit.

\section{METODE PENELITIAN}

Obyek-obyek yang dipapari sinar-X dalam penelitian yaitu kunci inggris dengan tebal diameter 5,68 mm; 3,99 $\mathrm{mm}$ dan 3,2 $\mathrm{mm}$ serta botol dan gabus berbentuk lingkaran. Pesawat sinar-X yang digunakan adalah mobile $x$-ray bermerk Siemens yang dimiliki oleh Rumah Sakit Nasional Diponegoro, Universitas Diponegoro, Semarang. Skema pengambilan citra obyek dan mobile $x$-ray yang digunakan dapat dilihat pada Gambar 2.

Masing-masing material tersebut dipapari sinar-X sebanyak satu kali yaitu sebesar $70 \mathrm{kV}$. Hasil citra dari kunci inggris, botol dan gabus tersimpan dalam kaset film yang kemudian 
akan dipindai pada sistem CR scanner di Rumah Sakit Negeri Diponegoro. Hasil citra kunci inggris, botol dan gabus yang telah dipindai tersebut akan tersimpan dalam bentuk file .dcm dan file .jpg. Hasil citra yang tersimpan dalam bentuk file .dcm kemudian akan ditampilkan pada aplikasi DICOM viewer yang telah terpasang pada smartphone.

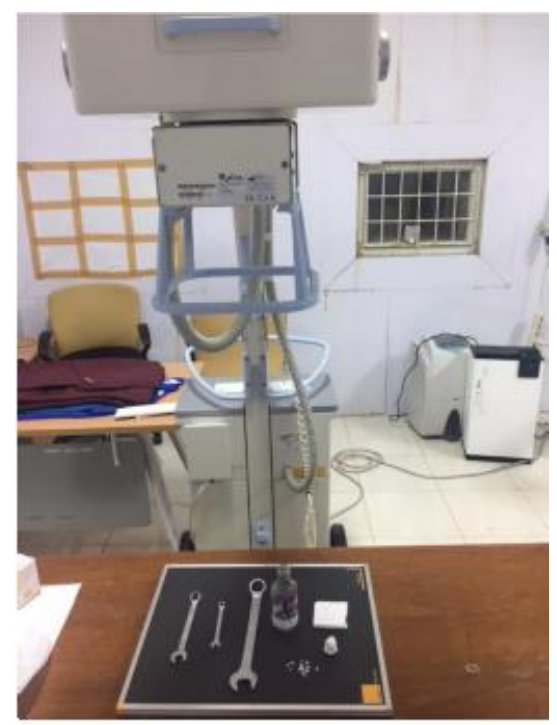

Gambar 2. Obyek-obyek yang dipapari

oleh sinar-X dari mobile $x$-ray yang digunakan
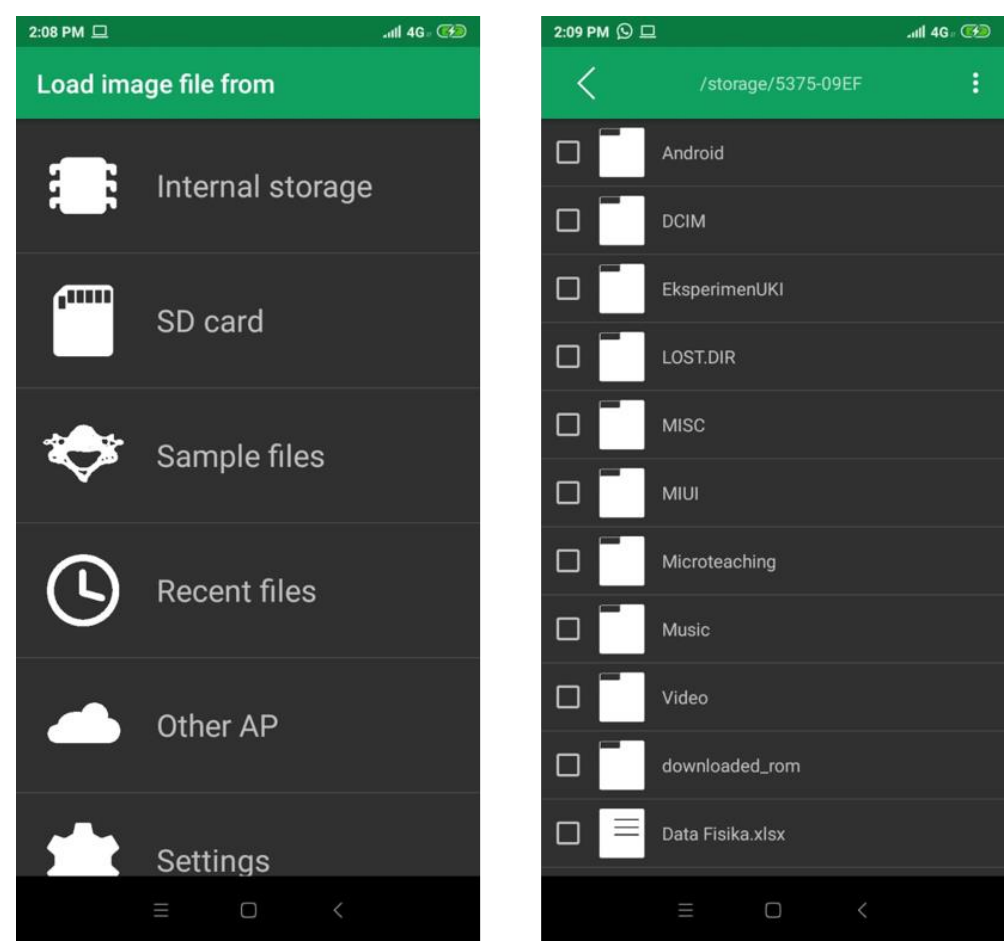

Gambar 3. Tampilan aplikasi DroidRender 3D DICOM Viewer 
Aplikasi yang digunakan tersebut adalah DroidRender 3D DICOM Viewer. Aplikasi DroidRender 3D DICOM Viewer adalah aplikasi smartphone yang digunakan untuk visualisasi maupun optimasi citra DICOM dan dapat diunduh secara gratis di Googleplay bersistem operasi Android. Aplikasi tersebut memiliki fitur-fitur lengkap seperti rekonstruksi $2 \mathrm{D} / 3 \mathrm{D}$, mesin rendering citra (volume rendering, $x$-ray simulation dan ray casting), segmentasi jaringan dan tampilan irisan 2D/3D.

Citra kunci inggris, botol dan gabus yang dibuka dalam aplikasi DroidRender 3D DICOM Viewer selanjutnya dioptimasikan dengan mengatur-atur kecerahan, kontras dan ketajamannya. Parameter utama yang terdapat dalam pengaturan citra adalah Window Width (WW) dan Window Center (WC). Kedua parameter tersebut merupakan ukuran yang biasa digunakan dalam pengolahan citra medis (radiografi konvensional, CT scan, MRI, PET Scan) untuk mendapatkan kecerahan dan kontras citra yang diinginkan. WW menunjukkan derajat keabuan suatu citra yang telah dipapari sinar-X dan nilainya bergantung pada penurunan intensitas sinar-X yang melewati suatu obyek sebagaimana ditunjukkan Persamaan 1. WL menunjukkan densitas (derajat kehitaman) citra yang dihasilkan.

Pada aplikasi DroidRender 3D DICOM Viewer, pengaturan dapat dilakukan secara sederhana dengan menggeser-geser citra sehingga didapatkan citra kunci inggris dan gabus yang optimal sehingga kemudian dapat dibandingkan dengan citra kunci inggris dan gabus dalam bentuk .jpg.

\section{HASIL DAN PEMBAHASAN}

Dari hasil eksperimen, pengaturan WW dan WC pada aplikasi untuk dapat menampilkan gabus secara optimal diperoleh pada nilai $\mathrm{WW}=2833$ dan $\mathrm{WC}=2170$. Citra dari kunci inggris, botol dan gabus dalam bentuk .jpg ditunjukkan pada Gambar 4 sementara citra hasil optimasi dengan mengggunakan aplikasi DroidRender 3D DICOM Viewer ditunjukkan pada Gambar 5. Dari kedua gambar tersebut dapat dilihat bahwa citra .jpg tidak dapat menampilkan gabus sementara citra hasil optimasi dapat menampilkan gabus. Hal tersebut karena pada proses pengolahan citra, file citra berekstensi .jpg sudah mengalami proses pemampatan (kompresi) ketika disimpan sementara file citra berekstensi DICOM tidak mengalami kompresi dalam penyimpanannya. Akibatnya, beberapa informasi citra (yang direpresentasikan dalam bentuk piksel) yang menyimpan detil tentang suatu citra terlihat hilang pada file berekstensi .jpg. 


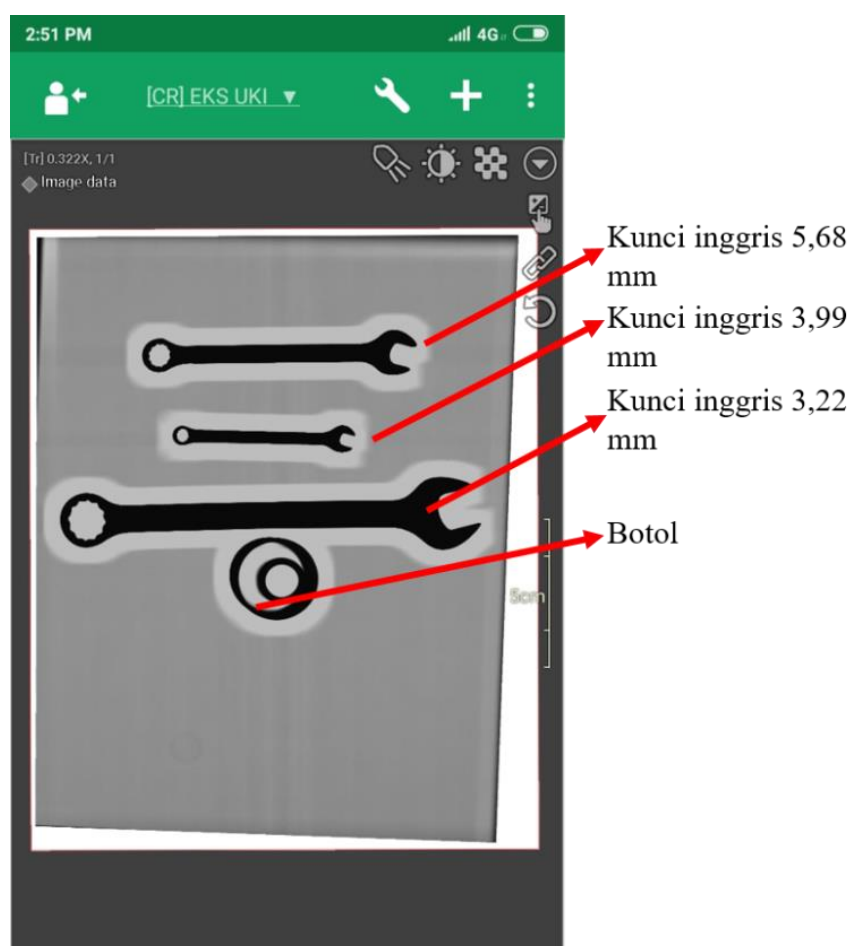

Gambar 4. Hasil citra berekstensi .jpg

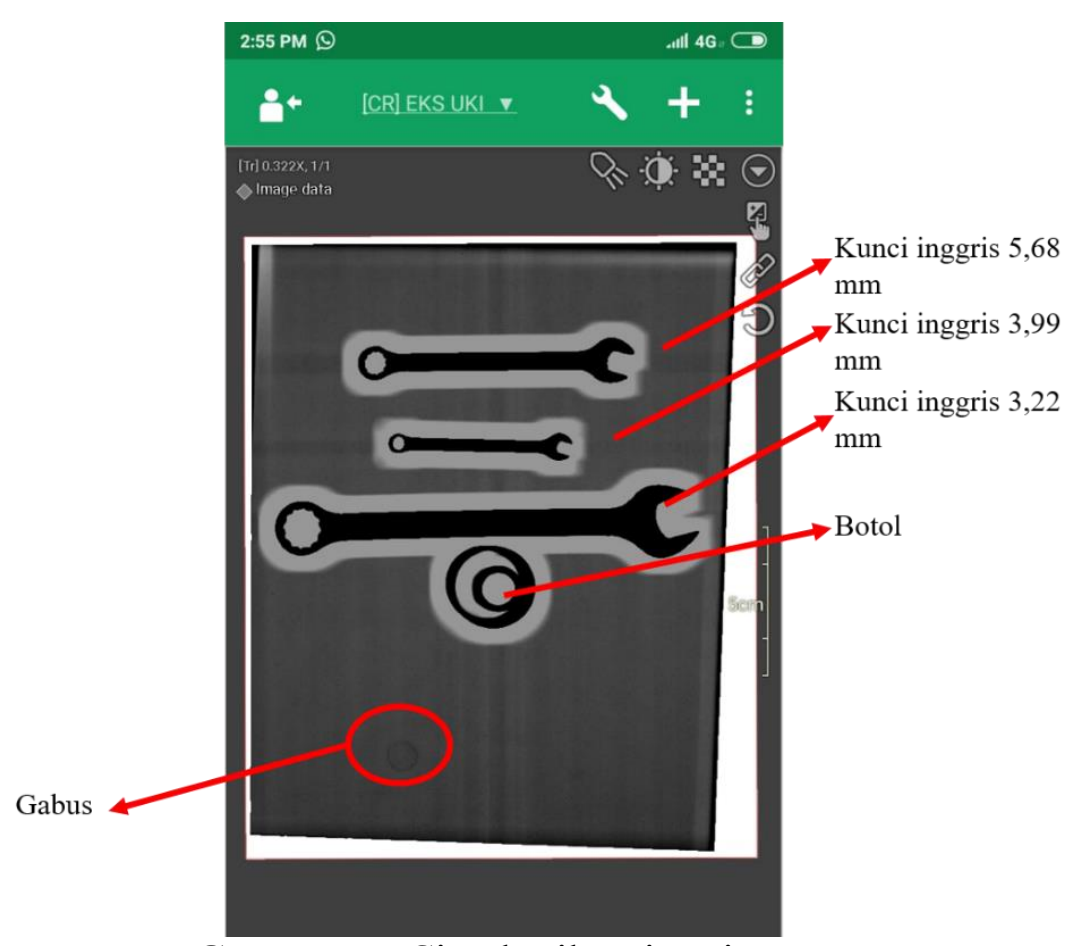

Gambar 5. Citra hasil optimasi

Selain itu, dengan aplikasi DroidRender 3D DICOM Viewer file-file berekstensi .dcm dapat diakses dengan mudah di smartphone sehingga praktisi medis dapat menganalisis bahkan mengoptimalisasi citra medis yang diinginkan secara mobile kapanpun dan di manapun. 


\section{KESIMPULAN DAN SARAN}

Informasi citra yang optimal yang digunakan dalam penelitian ini diperoleh ketika menggunakan DroidRender 3D DICOM Viewer dengan melakukan pengaturan nilai-nilai WC $=2833$ dan $\mathrm{WW}=2170$. Aplikasi DroidRender 3D DICOM Viewer memungkinkan praktisi medis untuk mengakses citra medis secara mobile sehingga ke depannya perlu dilakukan penelitian terkait optimasi citra medis yang rill seperti otak, kandung kemih ataupun jaringanjaringan tubuh lainnya.

\section{DAFTAR PUSTAKA}

Cabarkapa, S., Zajic, G., Pavlovic, M., Slavkovic, N., Reljin, N., \& Kragovic, M. (2009). System for Digitalization of Medical Images Based on DICOM Standard. Serbian Journal Of Electrical Engineering, 6(3), 409-4188.

Ee, C. S., Sim, K. S., Noh, N. (2010). Window Width Value Estimation Technique for CT Brain Images Using Average of Median of Statistical Central Moments. Int'l Conf. IP, Comp. Vision, and Pattern Recognition, Volume 2016, 93-99.

Hermen, J., Moll, C., Jahnen, A. (2010). Managing and Viewing DICOM Images with Image J.

Kristianto, B. (2010). Penggunaan Format DICOM untuk Mengatasi Perbedaan Kompatibilitas dalam Penyimpanan Data Rekam Medis. Jurnal Ilmiah untuk Peningkatan Profesional, 3(1), 65-74.

Muqmiroh, L., Setyanur, A., Maimanah, R., \& Witjaksono, B. P. (2018). The Effect of Window Width and Window-level Settings in Non-enhanced Head CT to Increase the Diagnostic Value of Subacute Ischemic Stroke. The 2nd International Conference on Vocational Higher Education (ICVHE) 2017, Volume 2018, 679-685.

Ningtias, D. R., Suryono, S., \& Susilo. (2016). Pengukuran Kualitas Citra Digital Computed Radiography Menggunakan Program Pengolah. Jurnal Pendidikan Fisika Indonesia, $12(2), 161-168$.

Suryaningsih, F., Kurnianto, K., \& Susanto, A. T. (2015). Pengujian Hasil Rekonstruksi Citra Radiografi Digital Menggunakan Program Labview. Jurnal Perangkat Nuklir, 9(2), 20-27.

Susilo, Sunarno, Swakarma, I. K., Setiawan, R., Wibowo, E. (2013). Kajian Sistem Radiografi Digital sebagai Pengganti Sistem Computed Radiography yang Mahal. Jurnal Fisika Indonesia, 17(50), 40-43.

Yogianto, H., Sutanto, T., Romeo. (2012). Rancang Bangun Aplikasi Dicom Viewer Pada Android Yang Terintegrasi Dengan PACS. Jurnal Sistem Informasi dan Komputer Akuntansi.

Xu, Y., He, S., \& Jia, C.-S. (2010). Approximate analytical solutions of the Klein-Gordon equation with the Pöschl-Teller potential including the centrifugal term. Physica Scripta, 81(4), 45001. https://doi.org/10.1088/0031-8949/81/04/045001. 